\title{
Object-Oriented Database Connectivity for Hand Held Devices
}

\author{
Vipin Saxena, Santosh Kumar
}

Department of Computer Science, Babasaheb Bhimrao Ambedkar University, Lucknow (U.P.), India.

Email: vsax1@rediffmail.com, sant7783@hotmail.com

Received March 6 ${ }^{\text {th }}, 2012$; revised April $3^{\text {rd }}, 2012$; accepted May $5^{\text {th }}, 2012$

\begin{abstract}
Due to the lack of representation of an object-oriented database on hand-held devices, the present work describes an approach to send the information in the form of an object-oriented database on hand-held devices. A smart phone is selected as a hand-held device and connectivity between the object-oriented databases has been established by the use of the object-oriented programming language C\#.Net. For modeling purpose, Unified Modeling Language (UML) is used to specify a UML Class Model and Sequence diagram. A concept of star schema is also used to represent the object-oriented database.
\end{abstract}

Keywords: UML; Object Orientation; Class Diagram; Sequence Diagram; SQL Server; Star Schema and C\#.Net

\section{Introduction}

UML is a powerful and graphical modeling language that is used to design the large and complex software systems. In the current scenario, the object-oriented approach is widely used by software professionals for the development purpose because of more flexibility towards the reusability of code and maintenance of the code in comparison of the structured design methodology. Let us first describe some of the important references related to UML. Booch [1] has described object-oriented analysis and design with various kind of applications along with various type of diagrams used for the stable software designs. Lieberherr, et al. [2] presented an objective sense of style for object-oriented programming. By lots of efforts of Gready, Object Management Group (OMG) [3] has released the version of UML in the year of 1997. The detailed description of UML is given by Selic and Rambaugh [4] they described the modeling of complex real-time system. Blaha and Premerlani [5] has presented an object-oriented modeling and designing approach for database applications. Rambaugh et al. [6] developed "The Unified Modeling Language Guide" for the user which provides help to operate UML. Blaha and Rambaugh [7] also described object-oriented modeling and design with UML. Berrabah et al. [8] has defined a new tool that checks the coherence of the constraints on UML diagrams. Haji Ali et al. [9] developed an assessment system through UML class diagram using the notation extraction. Prashanth and Chandrashekar [10] have pre- sented a new approach to detect faulty violations in UML state chart models. Palanippan and Ling [11] have described the several web-based case tools for automated rendering of UML model.

In addition to above, UML is also used to describe the software and hardware architecture problems. Saxena et al. [12-20] have proposed UML models for protocol establishing the mutual exclusion under distributed environment; for protection of domain based system by design of data cubes; for design of embedded database through the UML and further they developed a prototype for embedded database management system using $\mathrm{C}^{++}$ programming language. They also developed a UML models for the Patient Registration System with three dimensional data cubes; for instruction pipeline for the evaluation of performance of the instructions of software programs; for performance estimation of Karnaugh map with efficient new object-oriented algorithm. UML is also used by the authors for presentation and performance of various kinds of network topologies for distributed computer system. Recently, they developed UML model for performance evaluation of multithreaded programs on dual core processor. On the basis of UML design, performance of multithreaded programs written in JAVA and C\# has been computed. Maier G., et al [21] has casted a first look on mobile hand-held device with usage from a network perspective. Wu et al. [22] proposed a mobile system based application for content of Wikipedia. Kushwaha and Sharma [23] have presented data mining services where are able to support decision 
makers in strategic planning for the enhancement of small handheld devices. Peng et al. [24] also proposed a novel Markov Random Fields (MRF) based binarization algorithm segment foreground text from document images captured using hand-held devices (such as cellphone or digital camera). Morshed et al. [25] have presented an approach to identify the security and privacy related risks and threats of the mass users as well as corporate users, for the wireless hand-held devices and they have integrated with the clouds. Caban-Martinez et al. [26] has discussed the experience, advantages and disadvantages of touch screen handheld devices for the collection of field data from a largely underserved worker population. Martin-Dorta et al. [27] have attempted to harness the opportunities for mobility and the new user interfaces that handheld touch screen devices offer, in a non-formal learning context, with a view to developing spatial ability. Gember et al. [28] have stated the differences in the content and flow characteristics of handheld versus non-handheld traffic.

In the current scenario, many object-oriented languages are available for software development out of which C\# is a well known object-oriented programming language and supports several object-oriented concepts. Software professional are shifting their old structured based software into the object-oriented based software. Further desktop computing is shifting towards the hand held device computing. Therefore; in the present work, C\# is used to develop an application for connectivity of object-oriented database for hand-held device like smart phone. In the work, a real domain of the Life Insurance Corporation (LIC) of India is considered to develop the object-oriented database connectivity for said device. For the design purpose, UML is used to construct a UML class model and sequences of activities are also presented through UML sequence model. An Application is developed for connectivity of object-oriented database for said device and generated by the use of SQL Server 2008. The star schema is also designed for database with three major fields. For testing purpose, some queries have been performed to justify the performance of designed object-oriented database.

\section{UML Model for Object-Oriented Database Connectivity}

\subsection{UML Class Diagram}

The UML class diagram shows the structural behavior of the system, in which attributes and operations are designed for the complete software project. Different properties like association, aggregation, inheritances in the form of sub classes are also designed in the UML class diagram. In the present work, a complete process of depositing the premium of issued policy plan using mobile system is explained through UML class model which contains the major classes like as Customer, Mobile_System, Main_Branch, Plan, LIC_Branch_N and Bank represented in Figure 1.

The Main_Branch class has multiple associations with all the classes and single association with every Branch class of LIC i.e. LIC_Branch_N. The Plan class has a multiple associations with Customer class, and single association with the Main_Branch class. The Main Branch class sends information on the Customer's Mobile_System regarding Premium due of the issued plan for depositing the due amount. In Customer class, the customers interact with this information through the Mobile_System Class and go to the policy issuing branch through LIC_Branch_1, LIC_Branch_2, and LIC_Branch_ $\mathrm{N}$ for depositing the premium amount. After deposited the premium amount, the next premium due date is generated by the system through the software provided at the Main_Branch. The premium amount of the policy is auto deducted by the Main_Branch through the Bank which is linked to the every LIC's Branch. The Customer's data is uploaded online through the same software and also stored in the LIC's database. The details and the status of the premium of the policy can be viewed by fetching the database on the mobile system.

\subsection{UML Sequence Diagram}

The UML sequence diagram shows the dynamic behavior of the system. For the above, a UML sequence diagram is also designed and represented in Figure 2. From the figure, it is seen that Customer deposits the premium amount of the issued Policy in the LIC branch of India. The sequence diagram shows the complete process of depositing premium amount of an issued Policy. The five main objects are represented at the top of diagram. The communication line between two objects is shown by arrows along with communication message. The vertical line shows the life line of the object. The Main_Branch sends information about premium due to the Customer through the Mobile_System and the object Customer interacts with the information regarding premium due, then customer goes to the policy issuing branch and deposits the premium amount. After deposit the premium amount, the branch deposits the premium money into the Bank then the Main_Branch auto deducts the premium money. The main purpose of this diagram is to represent whether the system of sending information about premium due on the Mobile_System is working properly or not.

\section{Object-Oriented Database Connectivity}

\subsection{Design of Star Schema}

For designing the database, the business integration de- 


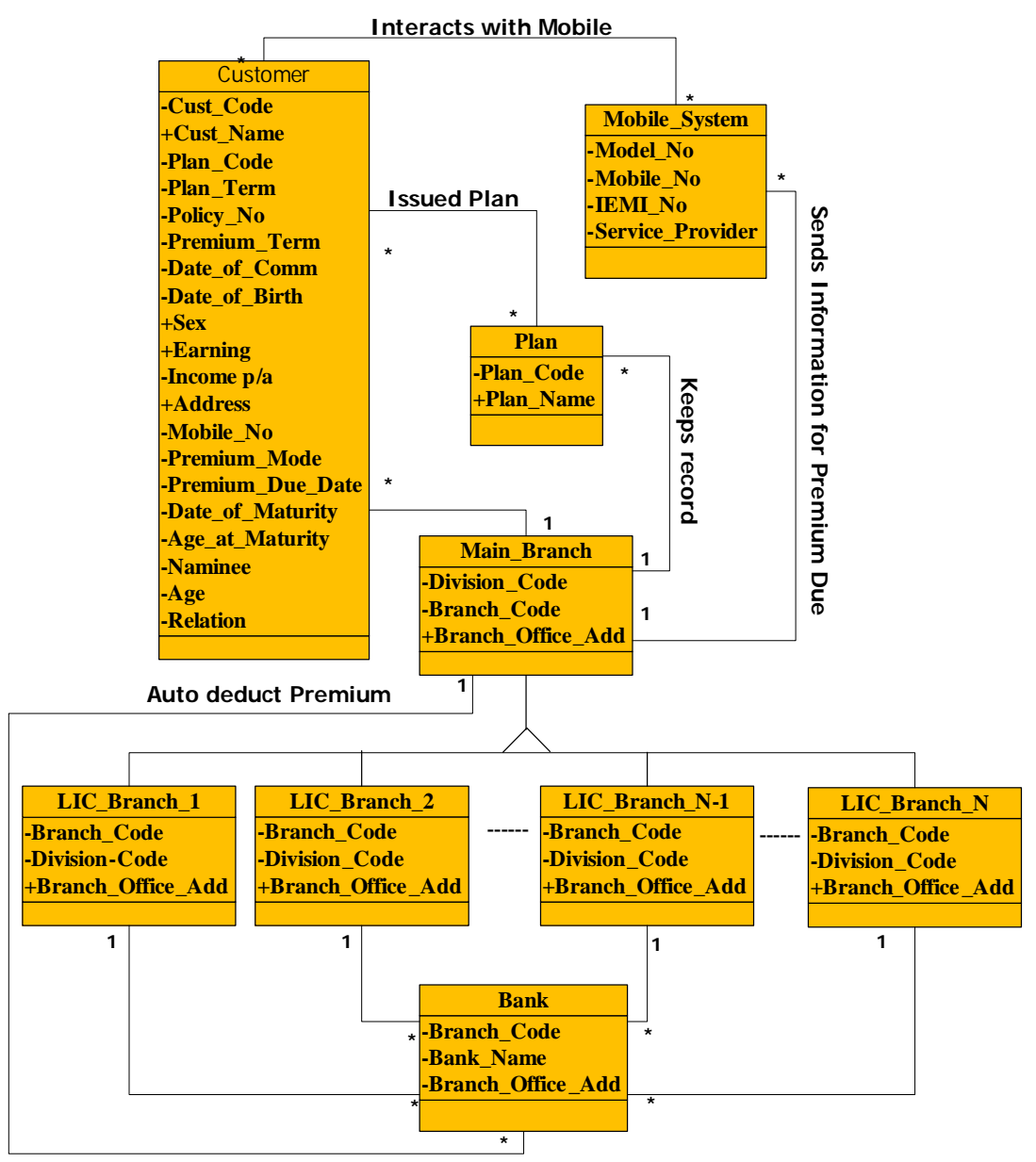

Figure 1. A UML class model.

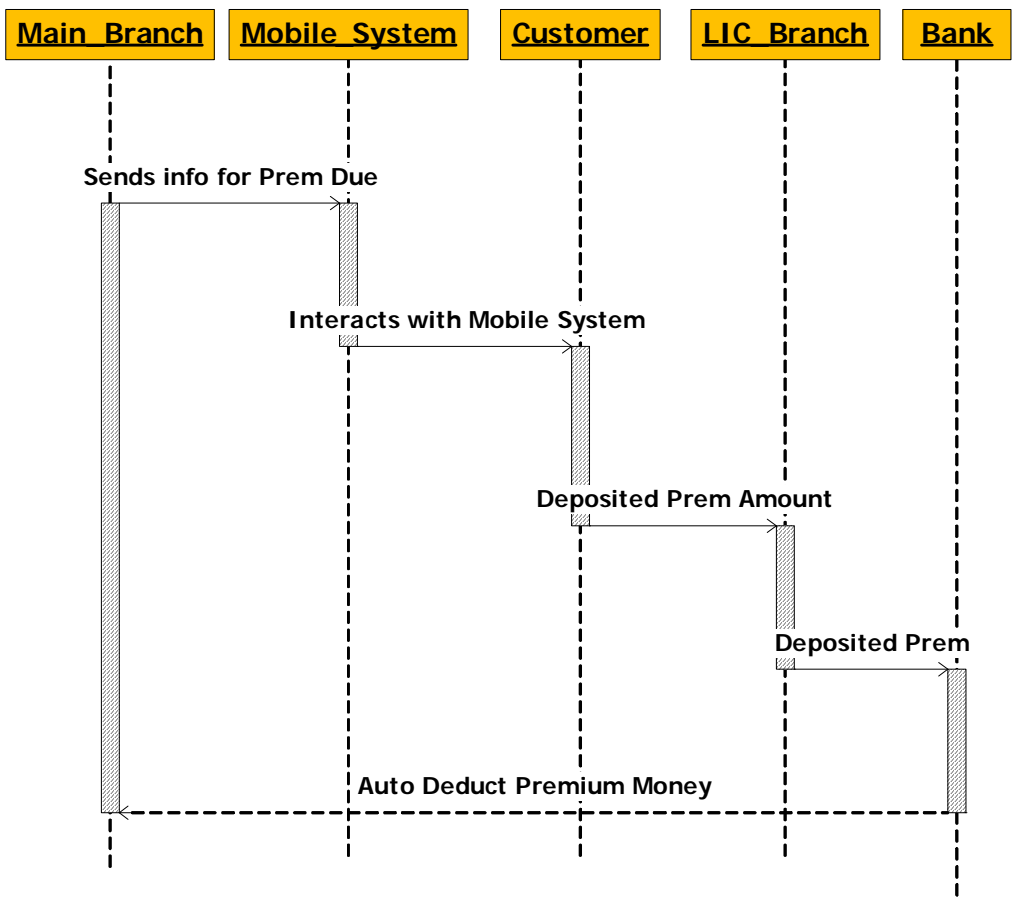

Figure 2. A UML sequence diagram. 
velopment services of SQL Server 2008 are used and a star schema is generated as shown in Figure $\mathbf{3}$ for connectivity of database. By the use of star schema, several database tables are generated and linked with one of the main table, which contains the primary key attributes of other tables.

\subsection{A Sample Object-Oriented Database}

For designing the database, authors have used the SQL Server 2008 and a database table is designed according to the attributes of customer table as shown as the output of Sample Query 1. It contains three major fields like Cust_Name (for customer name), Date_of_Commt (for date of commencement of policy) and Prem_Due_Date (for premium due date) of the issued policy plan. The purpose of this table is to take a look of customer name whose premium of issued policy is due. On the basis of this table, sample queries have been performed and corresponding results are given below:

Sample Query 1:

Select Cust_Name, Date_of_Commt;

Prem_Due_Date from tblCustomers;

The output of the above query is as follow:

\begin{tabular}{|c|c|c|c|c|}
\hline \multicolumn{5}{|c|}{ SQLQuery1.sqI - S...tosh kumar (51))* } \\
\hline \multicolumn{5}{|c|}{$\begin{array}{l}/ * * * * * * \text { Script for SelectTopNRows command fro] } \\
\square \text { SELECT } \text { TOP } 1000 \text { [Cust_Name] } \\
\text {, [Date_of_Commt] } \\
\text { [Prem_Due_Date] } \\
\text { FROM [LICPremium] [ [dbo] [ [tblCustomers }\end{array}$} \\
\hline \multicolumn{5}{|c|}{1 III } \\
\hline \multicolumn{5}{|c|}{ 畨 Results 首 Messages } \\
\hline & Cust_Name & Date_of_Commt & Prem_Due_Date & \\
\hline 1 & Maya Devi & $2010-07-28$ & 2011-01-27 & \\
\hline 2 & Kaushlendra Sengar & $2010-07-28$ & $2010-10-27$ & \\
\hline 3 & Pankaj Sivvastava & $2010-07-28$ & $2010-10-27$ & \\
\hline 4 & Sajeev Kumar & $2010-06-28$ & 2011-06-27 & \\
\hline 5 & Sirajuddeen Khan & $2010-07-28$ & $2010-10-27$ & \\
\hline 6 & Amit Kumar Singh & $2010-06-28$ & $2011-06-27$ & \\
\hline 7 & Siddhant Thakur & 2011-01-28 & $2011-04-27$ & \\
\hline 8 & Upendra Kumar & 2011-02-15 & 2011-03-14 & \\
\hline 9 & Shridhar & $2011-02-15$ & 2011-03-14 & \\
\hline 10 & DhanDevi & $2010-12-28$ & $2011-06-27$ & \\
\hline 11 & Ram Avtar & 2011-02-15 & 2011-07-14 & \\
\hline 12 & Mahesh Prasad & 2011-02-14 & 2011-08-13 & \\
\hline 13 & Rumila & $2011-01-28$ & 2012-01-27 & \\
\hline 14 & Ram Das & 2011-02-15 & $2012-02-14$ & \\
\hline 15 & Dharmendra Mishra & $2011-01-28$ & $2011-07-27$ & \\
\hline 16 & Dorilal & $2011-02-15$ & $2012-02-14$ & \\
\hline 17 & Islam Ali & 2011-01-28 & 2011-07-27 & \\
\hline 18 & Mithilesh Kumar & $2011-02-15$ & 2011-05-14 & \\
\hline 19 & Nitesh Kumar & 2011-02-15 & 2011-08-14 & \\
\hline 20 & Tavhid & $2011-02-15$ & 2011-05-14 & \\
\hline 21 & Saiyyada Khatoon & $2011-02-15$ & 2011-05-14 & \\
\hline
\end{tabular}

Sample Query 2:

select Cust_Name, Sum_Assured, Prem_Amount from

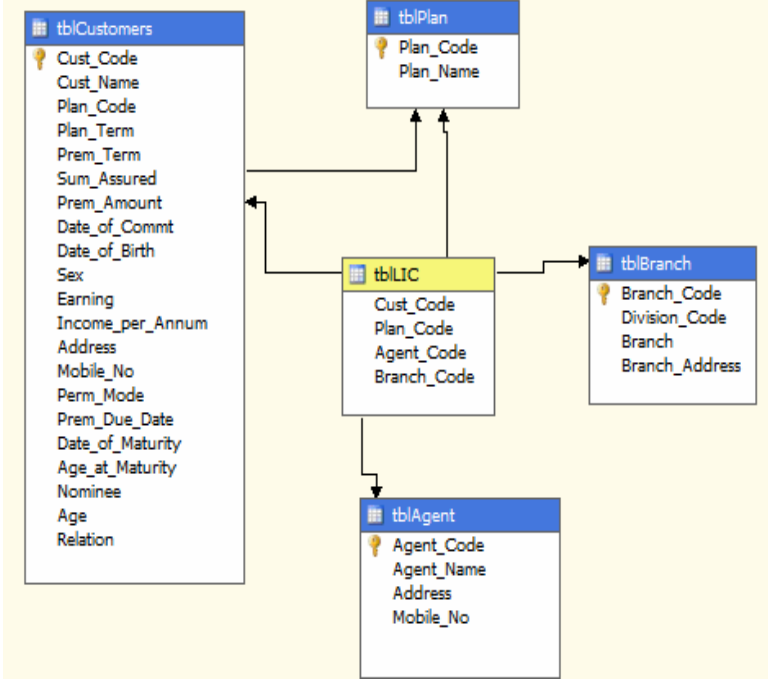

Figure 3. A sample of star schema.

tblCustomers where Cust_Code = 'C10009';

The output of the above query is given as:

\begin{tabular}{|l|l:ll|}
\hline & Cust_Name & Sum_Assured & Prem_Amount \\
\hline 1 & Shridhar & 100000 & 549 \\
\hline
\end{tabular}

Sample Query 3:

Select Prem_Due_Date,Prem_Amount from tblCustomers where Sex = 'Male';

The output of the above query is given as:

\begin{tabular}{|c|c|c|}
\hline 图 Results & \multicolumn{2}{|c|}{ 首 Messages } \\
\hline \multicolumn{2}{|r|}{ Prem_Due_Date } & Prem_Amount \\
\hline 1 & $2010-10-27$ & 319 \\
\hline 2 & $2010-10-27$ & 348 \\
\hline 3 & $2011-06-27$ & 25464 \\
\hline 4 & $2010-10-27$ & 766 \\
\hline 5 & $2011-06-27$ & 18408 \\
\hline 6 & $2011-04-27$ & 3264 \\
\hline 7 & 2011-03-14 & 445 \\
\hline 8 & $2011-03-14$ & 549 \\
\hline 9 & 2011-07-14 & 1723 \\
\hline 10 & $2011-08-13$ & 3752 \\
\hline 11 & $2012-02-14$ & 5715 \\
\hline 12 & $2011-07-27$ & 5940 \\
\hline 13 & $2012-02-14$ & 3793 \\
\hline 14 & $2011-07-27$ & 2861 \\
\hline 15 & $2011-05-14$ & 2000 \\
\hline 16 & $2011-08-14$ & 1004 \\
\hline 17 & $2011-05-14$ & 2016 \\
\hline 18 & $2011-12-27$ & 27501 \\
\hline 19 & $2011-08-14$ & 1591 \\
\hline os... & LICPremium $\mid 00$ & \begin{tabular}{l|l}
$00: 00$ & 19 rows
\end{tabular} \\
\hline
\end{tabular}

\section{Representation of Database}

\section{Connectivity on Mobile Devices}

For implementation of above concept, authors have used 
the Visual Studio 2008 and using C\#.Net, a window form is designed as shown in Figure 4. This diagram shows how to connect a mobile system with Personal Computer (PC) and sends an information regarding premium due on the customer's mobile system. The purpose of this application is to inform to the customers about their premium due of issued policy by the LIC of India through their mobile system.

The connectivity code segment for above application is given below:

private void btnsend_Click(object sender, EventArgs e)

\{

try

\{

//command for Connection to the database

if(DL.Con.State== ConnectionState.Open)

\{

//command for Sending the message

SqlCommand cmd = new SqlCommand();

cmd.Connection = DL.Con;

string SQLInsert = "INSERT INTO" + "tbloutbox phoneNO,Message,Delivery)” + "VALUES” + “(““ + txtPhoneNo.Text + ““, '“ + txtMessage.Text + ““,'send')”; cmd.CommandText = SQLInsert;

cmd.ExecuteNonQuery();

SMS.SendSMS(txtPhoneNo.Text, txtMessage.Text);

MessageBox.Show("Message Sent Successfully”,

"Santosh Kumar”); \}

//command for Disconnect from the database

DL.Con.Close();

\}

catch (Exception ex)

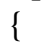
\}

MessageBox.Show(ex.Message);

\}

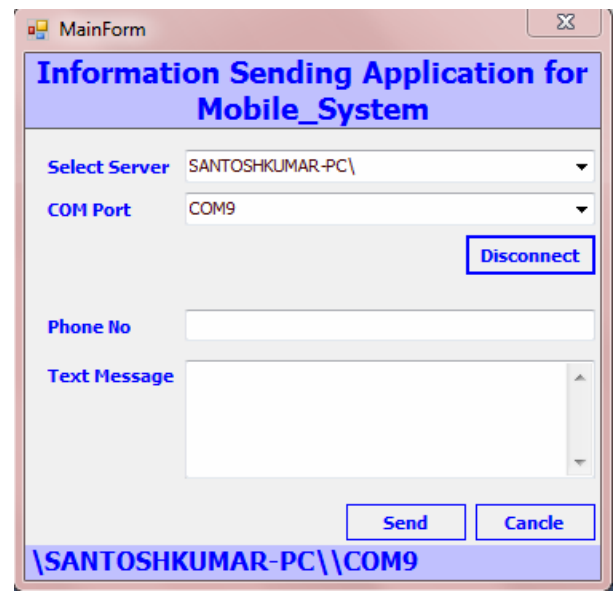

Figure 4. Windows application for mobile.
The Figure 5 shows the information which is sent successfully on the destination mobile device and Figure 6 shows the information which is reached at the destination mobile system.

\section{Concluding Remarks}

From the above work, it is concluded that UML is powerful modeling language for the development of the real models and it is also observed from the literature that UML is not much used for representation of the object-oriented database, therefore there is a need to construct more UML models for the software which are already running on the structured databases as object ori-

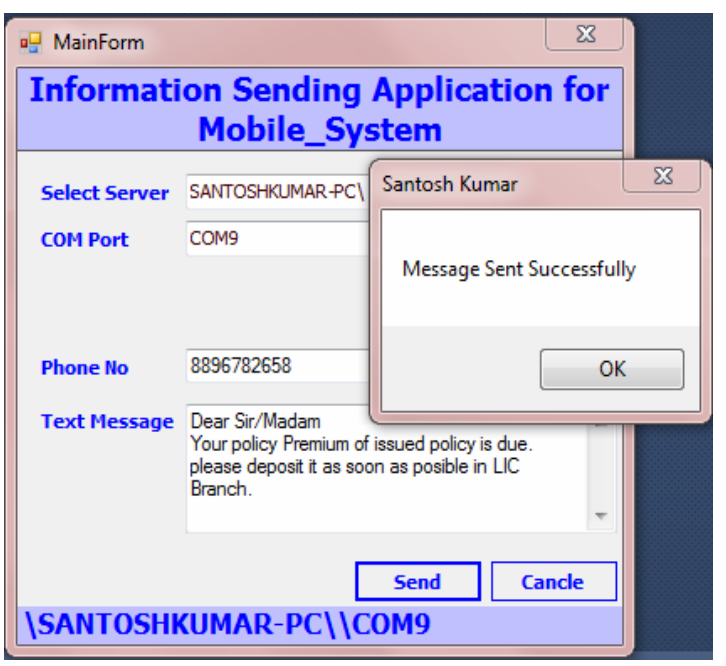

Figure 5. Message sent to destination.

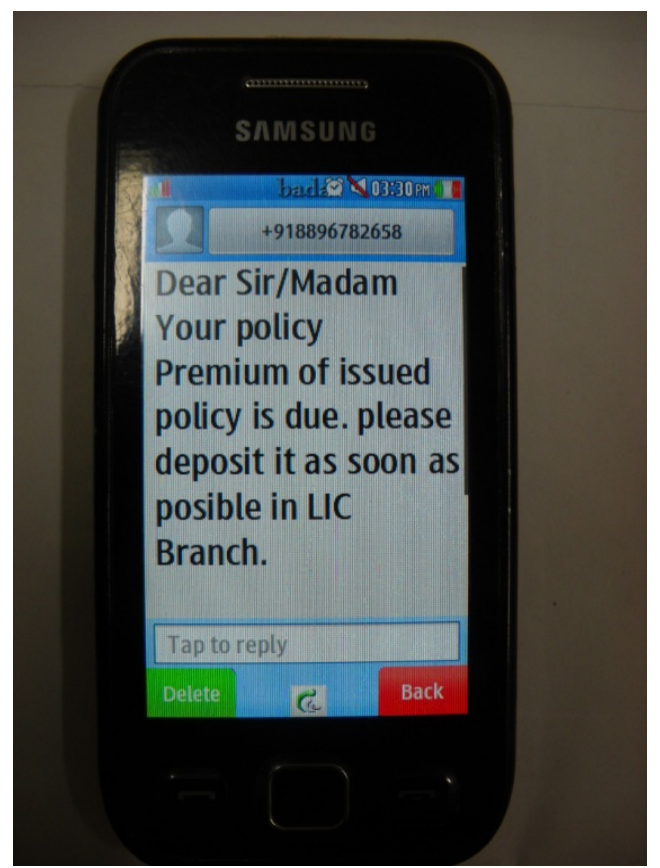

Figure 6. Display on mobile device. 
entation supports large amount of databases with flexible reusability property. In the asian/developing countries, there is a large scope for implementation of above approach to display the desired information from large databases on the mobile devices like pocket computer/mobile system, etc.

\section{Acknowledgements}

The authors are very thankful to University Grant Commission for providing Rajiv Gandhi National Fellowship as a financial support to carry out this research work. Thanks are also due to University Grant Commission, New Delhi, India for financial support to carry out this work.

\section{REFERENCES}

[1] G. Booch, "Object-Oriented Analysis and Design with Applications,” 2nd Edition, Addison-Wesley, 1994.

[2] K. Lieberherr, I. Holland and A. Rie, "Object-Oriented Programming: An Objective Sense of Style,” OOPSLA 88 Conference Proceedings on Object-Oriented Programming Systems, Languages and Applications, Vol. 23, No. 11, 1998, pp. 323-334.

[3] OMG, “Unified Modeling Language Specification,” 2011. http://www.omg.org

[4] B. Salic and J. Rambaugh, "Using UML for Modeling Complex Real-Time Systems,” 1998. http://www.relational.com/products/whitepapers/100230.jsp

[5] M. Blaha and W. Premerlani, "Object-Oriented Modeling and Design for Database Applications,” Prentice Hall, Upper Saddle River, 1998.

[6] J. Rambaugh, I. Jacobson and G. Booch, "The Unified Modeling Language User Guide,” Addison-Wesley, 1999.

[7] M. Blaha and J. Rambaugh, “Object-Oriented Modeling and Design with UML,” 2nd Edition, Prentice Hall, Upper Saddle River, 2005.

[8] D. Berrabah, F. Bouferes and C. Ducateau, “A New Tool to Check the Coherence of Constraints Defined on UML Class Diagrams," International Journal of Computer Science and Network Security, Vol. 6, No. 8B, 2006, pp. 162-171.

[9] N. Haji Ali, Z. Shukur and S. Idris, "Assessment System for UML Class Diagram Using Notation Extraction,” International Journal of Computer Science and Network Security, Vol. 7, No. 8, 2007, pp. 181-187.

[10] C. M. Prashanth and S. K. Chandrashekar, "A New approach to Detect Safety Violations in UML Statechart Models," International Journal of Computer Science and Network Security, Vol. 8, No. 7, 2008, pp. 167-174.

[11] S. Palanippan and L. Ling, "Web-Based CASE Tool for Automated Rendering of UML Model,” IJCSNS International Journal of Computer Science and Network Security, Vol. 8, No.8, 2008, pp. 146-152.

[12] V. Saxena and D. Arora, "UML Modeling of a Protocol for Establishing Mutual Exclusion in Distributed Computer
System,” International Journal of Computer Science and Network Security, Vol. 8, No. 6, 2008, pp. 227-235.

[13] V. Saxena and A. Gufran, "UML Modeling \& Protection of a Domain Based System," International Journal of Computer Science and Network Security, Vol. 8, No. 7, 2008, pp. 338-344.

[14] V. Saxena and D. Arora, "UML Modeling of Embedded Database through C++," IJCSNS International Journal of Computer Science and Network Security, Vol. 8, No. 10, 2008, pp. 104-113.

[15] V. Saxena, G. Ansari and K. Kumar, "Data Cube Representation of Patient Registration System through UML," IJCSNS International Journal of Computer Science and Network Security, Vol. 8, No. 10, 2008, pp. 319-324.

[16] V. Saxena and D. Raj, "UML Modeling of Instruction Pipeline Design,” World Academy of Science, Engineering and Technology, Vol. 42, 2008, pp. 263-266.

[17] V. Saxena, M. Srivastava and D. Arora, "Performance Estimation of Karnaugh Map through UML,” International Journal of Computer Science and Network Security, Vol. 9, No, 9, 2009, pp. 220-225.

[18] V. Saxena, D. Arora and M. Srivastava, "Performance Evaluation of Network System through UML," ACM SIGSOFT Software Engineering Notes, Vol. 34, No. 5, 2009, pp. 1-6. doi:10.1145/1598732.1598740

[19] V. Saxena and D. Arora, "UML Modeling of Network Topologies for Distributed Computer System," Journal of Computing and Information Technology-CIT, Vol. 17, No. 4, 2009, pp. 327-334. doi:10.2498/cit. 1001319.

[20] V. Saxena and M. Srivastava, "UML Modeling Performance Evaluation of Multithreaded Programs on Dual Core Processor," International Journal of Hybrid Information Technology, Vol. 2, No. 3, 2009, pp. 1-10.

[21] G. Maier, F. Schneider and A. Feldmann, "A First Look at Mobile Hand-Held Device Traffic,” PAM'10 Proceedings of the 11th International Conference on Passive and Active Measurement, Heidelberg, 7-9 April 2010, pp. 161-170.

[22] S. Wu, M. Li, P. C. Yang and T. Ku, "Ubiquitous Wikipedia on Handheld Device for Mobile Learning,” The 2010 6th IEEE International Conference on Wireless, Mobile, and Ubiquitous Technologies in Education, IEEE Computer Society, Washington DC, 12-16 April 2010, pp. 228-230.

[23] G. Kushwaha and N. Sharma, "A Survey on Mining Services for Better Enhancement in Small Hand Held Devices," International Journal of Computer Applications, Vol. 6, No. 1, 2010, pp. 40-43. doi:10.5120/1044-1351

[24] X. Peng, S. Setlur, V. Govindaraju and R. Sitaram, "Markov Random Field Based Binarization for Hand-Held Devices Captured Document Images,” Proceedings of the Seventh Indian Conference on Computer Vision, Graphics and Image Processing, New York, 12-15 December 2010, pp. 71-76. doi:10.1145/1924559.1924569

[25] M. S. J. Morshed, M. M. Islam, M. Q. Huq, M. S. Hossain and M. A. Basher, "Integration of Wireless Hand-Held Devices with the Cloud Architecture: Security and Privacy Issues,” 2011 International Conference on P2P, Parallel, Grid, Cloud and Internet Computing, Barcelona, 26-28 October 2011, pp. 83-88. doi:10.1109/3PGCIC.2011.22 
[26] A. J. Caban-Martinez, T. C. Clarke, E. P. Davila, L. E. Fleming and D. J. Lee, "Application of Handheld Devices to Field Research among Underserved Construction Worker Populations: A Workplace Health Assessment Pilot Study,” Environmental Health, 2011. http://www.ehjournal.net/content/10/1/27

[27] N. Martin-Dorta, J. L. Saorin and M. Contero, "Web-Based Spatial Training Using Handheld Touch Screen Devices,”
Educational Technology \& Society, Vol. 14, No. 3, 2011, pp. 163-177.

[28] A. Gember, A. Anand and A. Akella, "A Comparative Study of Handheld and Non-Handheld Traffic in Campus Wi-Fi Networks," 12th International Conference on Passive and Active Measurement, Heidelberg, 20-22 March 2011, pp. 173-183. 